\title{
Persistence of selected ammonium- and phosphonium-based ionic liquids in urban park soil microcosms
}

Sydow, Mateusz; Szczepaniak, Zuzanna; Framski, Grzegorz; Staninska, Justyna; Owsianiak, Mikolaj; Szulc, Alicja; Piotrowska-Cyplik, Agnieszka; Zgoa-Grzekowiak, Agnieszka; Wyrwas, Bogdan;

Chrzanowski, Lukasz

\section{Published in:}

International Biodeterioration \& Biodegradation

Link to article, DOI:

10.1016/j.ibiod.2015.04.019

Publication date:

2015

Document Version

Peer reviewed version

Link back to DTU Orbit

Citation $(A P A)$ :

Sydow, M., Szczepaniak, Z., Framski, G., Staninska, J., Owsianiak, M., Szulc, A., Piotrowska-Cyplik, A., ZgoaGrzekowiak, A., Wyrwas, B., \& Chrzanowski, L. (2015). Persistence of selected ammonium- and phosphoniumbased ionic liquids in urban park soil microcosms. International Biodeterioration \& Biodegradation, 103, 91-96. https://doi.org/10.1016/j.ibiod.2015.04.019

\section{General rights}

Copyright and moral rights for the publications made accessible in the public portal are retained by the authors and/or other copyright owners and it is a condition of accessing publications that users recognise and abide by the legal requirements associated with these rights.

- Users may download and print one copy of any publication from the public portal for the purpose of private study or research.

- You may not further distribute the material or use it for any profit-making activity or commercial gain

- You may freely distribute the URL identifying the publication in the public portal 


\section{Citation:}

2 Sydow, M., Szczepaniak, Z., Framski, G., Staninska, J., Owsianiak, M., Szulc, A., Piotrowska3 Cyplik, A., Zgoła-Grześkowiak, A., Wyrwas, B., Chrzanowski, Ł., 2015. Persistence of 4 selected ammonium- and phosphonium-based ionic liquids in urban park soil microcosms. 5 Int. Biodeterior. Biodegradation 103, 91-96. doi:10.1016/j.ibiod.2015.04.019 

microcosms

9 Mateusz Sydow ${ }^{1} *$, Zuzanna Szczepaniak ${ }^{2}$, Grzegorz Framski ${ }^{3}$, Justyna Staninska ${ }^{4}$, Mikołaj

10 Owsianiak $^{5}$, Alicja Szulc ${ }^{1}$, Agnieszka Piotrowska-Cyplik ${ }^{2}$, Agnieszka Zgoła-Grześkowiak ${ }^{1}$,

11 Bogdan Wyrwas ${ }^{1}$, Łukasz Chrzanowski ${ }^{1}$

$13{ }^{1}$ Faculty of Chemical Technology, Poznan University of Technology, Berdychowo 4, 60-965

14 Poznań, Poland

$15{ }^{2}$ Institute of Food Technology of Plant Origin, Poznan University of Life Sciences, Wojska

16 Polskiego 31, 60-624 Poznań, Poland

$17{ }^{3}$ Institute of Bioorganic Chemistry, Polish Academy of Sciences, Noskowskiego 12/14, 61-704

18 Poznań, Poland

$19{ }^{4}$ Department of Biotechnology and Food Microbiology, Poznan University of Life Sciences,

20 Wojska Polskiego 48, 60-627 Poznań, Poland

$21{ }^{5}$ Division for Quantitative Sustainability Assessment, Department of Management Engineering,

22 Technical University of Denmark, Produktionstorvet, Building 424, DK-2800 Kgs. Lyngby,

23 Denmark

*Corresponding author. Tel.: +48 6166537 16; fax: +48 616653649.

26 E-mail address: mateusz.sydow@gmail.com (M. Sydow)

\section{Abstract}

Knowledge about biodegradability of ionic liquids (ILs) in terrestrial systems is limited. Here, using urban park soil microcosms spiked with either ammonium- or phosphonium-based ILs

31 [didecyldimethylammonium 3-amino-1,2,4-triazolate, benzalkonium 3-amino-1,2,4-triazolate,

32 trihexyl(tetradecyl)phosphonium chloride, or trihexyl(tetradecyl)phosphonium 1,2,4-triazolate],

33 we studied their (i) 300-day primary biodegradation, and (ii) influence on $\mathrm{CO}_{2}$ evolution from the

34 microcosms. The primary biodegradation ranged from 21 to 33\% of total compound in the

35 dissolved phase. The evolution of $\mathrm{CO}_{2}$ from spiked microcosms was either lower or within the

36 range of background soil respiration, indicating no or small mineralization of the parent 
compounds and/or their metabolites, and their negligible or small toxicity to soil microorganisms.

Our results suggest the potential for persistence of the four studied ILs in urban park soils.

Keywords: impact assessment; ionic liquids; risk assessment; terrestrial toxicity;

41 biotransformation;

\section{Introduction}

44 Ionic liquids (ILs) are a group of chemicals composed of an organic cation and an organic or 45 inorganic anion. Due to a large number of cation - anion combinations, the number of ILs which 46 may be obtained is tremendous (up to $10^{18}$ ) (Rogers and Seddon 2003). Various ILs are currently

47 applied in catalysis and biocatalysis, and in organic synthesis (e.g., multi-ton scale use of 48 imidazolium-based IL in the BASIL ${ }^{\mathrm{TM}}$ process developed by BASF) (Plechkova and Seddon 2008; Quijano et al. 2010). Although there are no reports providing information about the presence of ILs in water or soil ecosystems yet, the increasing use of ILs in the industry is

51 expected to lead to environmental pollution. Consequently, there has been an increasing number

52 of studies dealing with ILs behaviour and impact on the environment (Ranke et al. 2007;

53 Petkovic et al. 2010; Pham et al. 2010; Cvjetko Bubalo et al. 2014).

Low volatility of ILs excludes emission into air as an exposure route, but there can be direct release routes to freshwater or soil. It is generally thought that relatively high thermal and chemical stability of ILs contributes to their low biodegradability (Quijano et al. 2011; Neumann et al. 2012), primarily on aquatic environments (Coleman and Gathergood 2010; Ford et al. 2010; Stolte et al. 2011). In soils, Modelli et al. (2008), demonstrated that at the end of a 180-day respirometric experiment, none of the four imidazolium-based ILs was mineralized completely, and the amount of $\mathrm{CO}_{2}$ evolved depended on both the type of cation and the type of anion.

61 Primary biodegradation, defined as an alteration in the chemical structure of a substance, brought about by biological action, resulting in the loss of a specific property of that substance (OECD 301, 1992), has been studied and formation of biotransformation products has also been documented (Stolte et al. 2008; Pham et al. 2009; Docherty et al. 2010). Sorption of ILs onto the soil matrix can occur, depending on soil parameters (such as organic carbon content or cation exchange capacity), which can lead to a decrease of their bioavailability and biodegradability and

67 contribute to the potential persistence (Stepnowski et al. 2005; Studzińska et al. 2008; Mrozik et 
al. 2012). Most published studies focused on toxicity of ILs to single, isolated microbial strains (Pham et al. 2010; Cvjetko Bubalo et al. 2014), but little is known about the influence of ILs on the activity of soil microbiota. Recently, Peric et al. (2014), showed that aprotic ILs inhibited soil respiration in the concentration range from $100 \mathrm{mg} \mathrm{kg}^{-1}$ to $10,000 \mathrm{mg} \mathrm{kg}^{-1}$ depending on the ILs 72 structure.

The aim of our study was to investigate primary biodegradation of ammonium- and phoshonium-based ILs in urban park soil microcosms, simulating an accidental spill, and their influence on $\mathrm{CO}_{2}$ evolution from the microcosms. The four ILs studied were: (i) didecyldimethylammonium 3-amino-1,2,4-triazolate ([DDA][3AT]), (ii) benzalkonium 3-amino1,2,4-triazolate ([BDA][3AT]), (iii) trihexyl(tetradecyl)phosphonium chloride ([ $\left.\left.\mathrm{P}_{66614}\right][\mathrm{Cl}]\right)$, and (iv) trihexyl(tetradecyl)phosphonium 1,2,4-triazolate $\left(\left[\mathrm{P}_{66614}\right][\mathrm{Tr}]\right)$. Apart from $\left[\mathrm{P}_{66614}\right][\mathrm{Cl}]$, the studied ILs have antifungal properties. The triazole-based ILs were previously described as novel anti-microbial and anti-fungal plant protection agents with a broad spectrum of activity (Walkiewicz et al. 2010), and are thus expected to be toxic to the microorganisms present in the soil. An urban park soil of known biodegrading potential toward petroleum hydrocarbons (Sydow et al. unpublished results) was employed. The primary biodegradation (300-day) was studied by measuring ILs' residues in the soil, while $\mathrm{CO}_{2}$ evolution from spiked microcosms was measured using a respirometric test.

\section{Materials and methods}

\subsection{Synthesis of ionic liquids}

The ammonium-based ILs were synthesised with the use of quartemary ammonium bromides, which were obtained in reaction of equimolar amount of amine (decyldimethylamine or benzyldimethylamine) with appropriate bromoalkane (1-bromodecane or 1-bromododecane respectively). The reaction was carried out using anhydrous acetonitrile as solvent at $70^{\circ} \mathrm{C}$ for 24 h. After cooling the reaction mixture to room temperature, quaternary ammonium bromides were precipitated by adding cold ethyl acetate. The bromides were filtered and dried under vacuum at $50^{\circ} \mathrm{C}$. Product yield was over 95\%. Next, 3-amino-1,2,4-triazolate ILs were prepared by in situ

97 deprotonation of corresponding azole with sodium or potassium hydroxide in methanol and 98 mixed with an equimolar amount of appropriate quaternary ammonium bromides, according to 
99

100

101

102

103

104

105

106

107

108

109

110

111

112

113

114

115

116

117

118

119

120

121

122

123

124

125

126

127

128

129

the method described in Walkiewicz et al. (2010). The phosphonium-based ILs were prepared according to method described by Cieniecka-Rosłonkiewicz et al. (2005). Briefly, trihexyl(tetradecyl)phosphonium chloride was prepared in reaction of trihexylphosphine and 1bromotetradecane. The 1,2,4-triazolate was obtained by in situ deprotonation of corresponding azole with sodium hydroxide in methanol, followed by reaction with chloride precursor. Water content of the synthesized ILs was determined by Karl Fisher method for all prepared compounds, and was less than $0.1 \%$. The list of the studied ILs is given in Table 1 .

\subsection{Soil}

The soil used in the experiments was collected from a city park in Poznań, Poland (N 52.4011445, E 16.9222993) and according to Unified Soil Classification System, was characterized as fine grained silt loam type OL belonging to organic silts and organic silty clays of low plasticity. The composition of experimental soil was as follows: clay $4 \pm 1$ [\%]; silt $83 \pm 3$ [\%]; sand $13 \pm 2$ [\%]. Detailed characteristics of the soil: organic carbon $5.44 \pm 0.31$ [g kg-1]; nitrogen $0.57 \pm 0.07\left[\mathrm{~g} \mathrm{~kg}^{-1}\right.$ ]; phosphorous $0.080 \pm 0.005\left[\mathrm{~g} \mathrm{~kg}^{-1}\right]$; $\mathrm{pH} 6.95 \pm 0.7$; bulk density $1.41 \pm 0.06\left[\mathrm{Mg} \mathrm{m}^{-3}\right]$; porosity $0.455 \pm 0.03\left[\mathrm{~m}^{3} \mathrm{~m}^{-3}\right]$; moisture $18 \pm 1$ [\%]; cation exchange capacity $22.1 \pm 0.8\left[\mathrm{cmol}_{\mathrm{c}} \mathrm{kg}^{-1}\right]$. A sign \pm represents standard deviation $(\mathrm{n}=3)$.

\subsubsection{Primary biodegradation}

Each primary biodegradation experiment was set up with four replicates. Three replicates were used to analyse ions residues with the use of HPLC-MS, while one replicate was used for moisture monitoring over the course of the experiment. The samples were prepared as follows: 10 g of non-sterilized soil was added into bottles and then spiked with a methanol solution of each IL to reach an approximate concentration of $4000 \mathrm{mg} \mathrm{kg}^{-1}$ of IL per sample. The concentration in this range is typically used in hydrocarbon biodegradation tests (Lisiecki et al. 2014). Next, methanol was evaporated with nitrogen. Afterwards, untreated soil in the amount of 90 grams was added. The soil was later vigorously mixed. Finally, the microcosms were incubated at $20^{\circ} \mathrm{C}$ for 300 days. The soil moisture was determined once a week by using moisture analyser (RADWAG MA 110.R, Poland), and adjusted to 18\% if necessary. After 300 days three $0.5 \mathrm{~g}$ samples of each bottle replicate (giving nine sampling points for each studied IL) were subjected to three-step ultrasound assisted extraction with methanol ( $3 \times 1 \mathrm{~mL})$ and analysed by HPLC-MS 
130

131

132

133

134

135

136

137

138

139

140

141

142

143

144

145

146

147

148

149

150

151

152

153

154

155

156

157

158

159

to determine the residual masses of ILs ions. Controls were prepared as above, except that the urban soil was previously sterilized in order to investigate the influence of sorption on primary biodegradation of the compounds. The soil was divided into aliquots of $30 \mathrm{~g}$, frozen, placed in sealed polyethylene bags and irradiated at 40,000 grey using a ${ }^{192}$ Ir source (Alef and Nannipleri 1995). Afterwards, a solution of selected IL was added to $10 \mathrm{~g}$ of sterilized soil. Next methanol was evaporated and untreated sterilized soil in the amount of 90 grams was added and samples were mixed vigorously. After 300 days of incubation under sterile conditions, soil from each replicate was used in order to determine the fraction of ILs that was not sorbed onto soil matrix. For this purpose three $0.5 \mathrm{~g}$ samples of each bottle replicate (giving nine samples in total) were subjected to three-step ultrasound assisted extraction with methanol (3 x $1 \mathrm{~mL}$ ) and analysed by HPLC-MS.

The primary biodegradation of selected ILs was calculated with regard to initial masses of ILs at the beginning of the experiment, residual masses of cations and anions at the end of the experiment and percentage values of ILs fraction sorbed onto studied soil. It was not possible to determine the residual anion amount for $\left[\mathrm{P}_{66614}\right][\mathrm{Tr}]$, since the employed analytical method did not allow it. The residues of [Cl] anion were not analysed, since halide ILs undergo hydrolysis reaction in the environment. Therefore, in the case of both phosphonium-based ILs primary biodegradation was calculated ignoring the final mass of the anion. Thus, primary biodegradation of ammonium- and phosphonium-based ILs cannot be compared directly. The primary biodegradation was calculated as presented in Eq. 1.

$$
P B=100 \%-\frac{M_{C} B_{C}+M_{A} \cdot x_{A}}{M_{I L}}-F S_{I L}
$$

where:

$P B$ - primary biodegradation of IL [\%];

$M_{C}$ - residual mass of cation at the end of the experiment [g];

$M_{A}$ - residual mass of anion at the end of the experiment [g];

$M_{I L}$ - initial mass of IL at the beginning of the experiment [g];

$X_{C}$ - percentage of molar mass of cation in overall molar mass of IL [\%];

$X_{A}$ - percentage of molar mass of anion in overall molar mass of IL [\%];

$F S_{I L}$ - the sorbed fraction of IL onto soil matrix [\%]. 
161 The sorbed fraction of each IL was calculated with regard to mass of extracted IL and mass of

162 introduced IL as presented in Eq. 2.

$$
F S_{I L}=\left(1-\frac{M_{E}}{M_{I}}\right) \cdot 100 \%
$$

165

166

167

168

169

170

171

172

173

174

175

176

177

178

179

where:

$$
\begin{aligned}
& M_{E}-\text { mass of extracted IL [g]; } \\
& M_{I} \text { - mass of introduced IL [g]. }
\end{aligned}
$$

\subsubsection{HPLC-MS analysis}

Three $1 \mathrm{~mL}$ soil extracts of each sampling point (obtained via three-step extraction of each $0.5 \mathrm{~g}$ soil sample) were combined, filtered through a $0.2 \mu \mathrm{m}$ PTFE syringe filter and diluted with methanol : water solution (80:20 v/v). The HPLC-MS analyses were performed with the UltiMate 3000 RSLC chromatograph from Dionex (Sunnyvale, CA, USA). Five $\mu$ L samples were injected into a Hypersil GOLD column $(100 \mathrm{~mm} \times 2.1 \mathrm{~mm}$ I.D.; $1.9 \mu \mathrm{m})$ with a $2.1 \mathrm{~mm}$ I.D. pre-filter cartridge $(0.2 \mu \mathrm{m})$ from Thermo Scientific (Waltham, MA, USA). The mobile phase consisted of $5 \times 10^{-3} \mathrm{~mol} \mathrm{~L}^{-1}$ ammonium acetate in water (phase A) and methanol (phase B) at a flow rate of 0.2 $\mathrm{mL} \mathrm{min}^{-1}$. Gradient elution was performed by linearly increasing the percentage of phase B from 85 to $100 \%$ in $4 \mathrm{~min}$ and maintained at $100 \%$ for $3 \mathrm{~min}$. The LC column effluent was directed to the API 4000 QTRAP triple quadrupole mass spectrometer from AB Sciex (Foster City, CA, USA) through the electrospray ionization source (Turbo Ion Spray) that operated in positive ion mode for analyses of cations and in negative ion mode for analyses of anions. The dwell time for each mass transition detected in the MS/MS multiple reaction monitoring mode was set to 200 ms. Nitrogen was used as curtain gas (10 psi), nebulizer gas (40 psi), auxiliary gas (45 psi) and collision gas (medium). The source temperature was $400^{\circ} \mathrm{C}$ and the ion spray voltage was $4500 \mathrm{~V}$ for cations and $-4500 \mathrm{~V}$ for anions. The declustering potential was $50 \mathrm{~V}$ for cations and $-50 \mathrm{~V}$ for anions.

\subsection{Evolution of $\mathrm{CO}_{2}$ from the microcosms}


Each experiment was performed in triplicate. Microcosms were prepared as follows: $10 \mathrm{~g}$ of nonsterilized soil was added to 1L glass SIMAX bottles closed with PP screw caps and later spiked with a methanol solution of each IL to reach an approximate concentration of $4000 \mathrm{mg} \mathrm{kg}^{-1}$ of IL per sample. Next, methanol was evaporated with nitrogen. Afterwards, 90 grams of untreated soil were added and the soil was vigorously mixed. Finally, the microcosms were incubated at $20^{\circ} \mathrm{C}$ for 300 days. The amount of emitted $\mathrm{CO}_{2}$ was determined according to respirometric tests procedure. Additionally, a set of three control replicates - bottles containing $100 \mathrm{~g}$ of nonsterilized urban park soil without any addition of IL - was prepared. The controls were prepared to investigate the background respiration of the used soil. Natural soil respiration was determined according to respirometric tests procedure.

The evolution of $\mathrm{CO}_{2}$ in each soil sample was determined periodically by measuring $\mathrm{CO}_{2}$ content in base traps (10 mL of $0.75 \mathrm{M} \mathrm{NaOH}$ in a $20-\mathrm{mL}$ vial) placed in the microcosms (bottles with the used urban park soil) as described elsewhere (Szulc et al. 2014; Lisiecki et al. 2014). Each bottle contained one base trap. $\mathrm{NaOH}$ and $\mathrm{Na}_{2} \mathrm{CO}_{3}$ from each trap were titrated with $0.1 \mathrm{M}$ $\mathrm{HCl}$ using an automatic titrator (Metrohm titroprocessor 686). The content of the base traps was replaced with fresh $\mathrm{NaOH}$ solution after each measurement.

\subsection{Statistical analyses}

One-way analyses of variance (ANOVA), $\alpha=0.05$ were performed to detect significant differences between the treated groups and the respective controls. All of the presented error bars represent standard errors of the mean (for primary biodegradation tests $n=9$, for $\mathrm{CO}_{2}$ evolution tests $n=3)$.

\section{Results and discussion}

Below, we present results for primary biodegradation, sorption, $\mathrm{CO}_{2}$ evolution, and carbon balance of the four studied ILs in soil microcosms. Formation of biotransformation products and potential biotransformation mechanisms, are then discussed.

\subsection{Primary biodegradation and sorption}


218 Figure 1a shows that 300-day primary biodegradation of the four studied ammonium- and 219 phosphonium-based ILs in urban park soil microcosms was small. It reached 33 and $21 \%$ of the 220 total compound in the dissolved phase for the two ammonium-based ILs ([DDA][3AT] and 221 [BDA][3AT], respectively), and 25 and 29\% for the two phosphonium-based ILs ([P $\left.{ }_{66614}\right][\mathrm{Cl}]$ 222 and $\left[\mathrm{P}_{66614}\right][\mathrm{Tr}]$, respectively). Figure 1b shows that the sorbed fraction of the studied ILs in soils 223 was generally higher for the two ammonium-based ILs, reaching 44 and 64\% for [DDA][3AT] 224 and [BDA][3AT], respectively, as opposed to 13 and $29 \%$ for $\left[\mathrm{P}_{66614}\right][\mathrm{Cl}]$ and $\left[\mathrm{P}_{66614}\right][\mathrm{Tr}]$, 225 respectively. Thus, the IL with longer alkyl chain (i.e., [BDA][3AT]) exhibited higher sorption 226 onto soil as compared to the shorter-chain alternative (i.e., [DDA][3AT]), and furthermore the IL 227 with inorganic anion (i.e., $\left.\left[\mathrm{P}_{66614}\right][\mathrm{Cl}]\right)$ is the least sorbed among the four studied ILs. Both

228 findings are in agreement with Studzinska et al. (2008) who showed how sorption of ILs onto soil 229 depends on the side chain length and on the cation-anion combination. In soils, biodegradation of 230 organic compounds can be influenced by their bioavailability for microbial uptake from the 231 dissolved phase (Alexander 2000). However, differences in sorption between the studied ILs do 232 not translate directly into apparent differences in primary biodegradation, suggesting that the 233 persistence of the four ILs is rather due to their low inherent biodegradability than due to 234 bioavailability restrictions in the soil matrix.

236 3.2. Evolution of $\mathrm{CO}_{2}$ and carbon balance

237 Figure 2a shows that $\mathrm{CO}_{2}$ evolution from spiked microcosms was slightly below or within range 238 of background soil respiration, indicating no or small negative effect of the studied ILs on 239 respiratory activity of microbiota in the soil. Only in the case of [BDA][3AT], were statistically 240 significant differences between the microcosms spiked with ILs and the control microcosm 241 observed. These findings from a long-term soil microcosm experiment are not in disagreement 242 with findings from biodegradation tests performed in aquatic systems for structurally similar ILs. 243 In a manometric respiratory test with activated sludge, Pisarova et al. (2012) showed that one 244 (i.e., (2-hydroxyethyl)-trimethylammonium methanesulphonate) out of three ammonium-based 245 ILs reached 74\% of ultimate biodegradation within 28 days. The two other ILs (i.e., tributyl246 methylammonium methanesulphonate and butyl-trimethylammonium methanesulphonate) 247 reached 7 and 4\%, respectively. In a $\mathrm{CO}_{2}$ headspace test, also Atefi et al. (2009) showed that 
ultimate biodegradation of various tri- $n$-hexylphosphonium-based ILs in an aqueous medium after 28 days ranged from 0 to 30\%, depending on the side chain functionality.

The largest $\mathrm{CO}_{2}$ evolution was measured for the microcosms spiked with $\left[\mathrm{P}_{66614}\right][\mathrm{Cl}]$. We therefore performed carbon balance to see how much of the primarily biodegraded $\left[\mathrm{P}_{66614}\right][\mathrm{Cl}]$ could be mineralized. Even if the $\mathrm{CO}_{2}$ evolution from that microcosms had been statistically different from that measured for the control, and assuming yield of $0.4 \mathrm{~g}$ of microbial carbon per $1 \mathrm{~g}$ of IL carbon, $63 \%$ of the primarily biodegraded $\left[\mathrm{P}_{66614}\right][\mathrm{Cl}]$ in the dissolved phase could be mineralized. This corresponds to 16\% mineralization of total compound. For the three other ILs, measured $\mathrm{CO}_{2}$ evolution was much lower compared to theoretical $\mathrm{CO}_{2}$ evolution expected if all primarily biodegraded ILs had been mineralized (and assuming a yield of $0.4 \mathrm{~g}$ of microbial carbon per $1 \mathrm{~g}$ of IL) (Figure 2b). This confirms no, or very small, ultimate biodegradation of the four studied ILs in our soil microcosms and suggests that biotransformation products must have formed in the microcosms. Further, one IL (i.e., [BDA][3AT]), showed $\mathrm{CO}_{2}$ evolution values lower as compared to the control, suggesting some, albeit small, inhibition of soil microbial activity in the microcosm spiked with this IL at total concentration of $4000 \mathrm{mg} \mathrm{kg}^{-1}$. Peric et al. (2014) showed, that for various imidazolium-based ILs, inhibition of respiratory activity of the soil can occur in concentration range of 100 to $10,000 \mathrm{mg} \mathrm{kg}^{-1}$, depending on the IL structure.

\subsection{Potential biotransformation mechanisms}

Metabolites of primary biodegradation of the studied ILs were expected to form in our microcosms, because all four ammonium- and phosphonium-based ILs have long, unbranched alkyl chains attached to the nitrogen or phosphorus atom in the organic cation. Stolte et al. (2008) already showed that $\omega$-oxidation on the terminal methyl group in alkyl chains of imidazoliumbased ILs occurs, leading to the formation of shorter-chained products with carboxylic group.

272 Also Pham et al. (2009) and Zhang et al. (2011) showed gradual degradation of ILs' alkyl chains during biotransformation by activated sludge, or by Pseudomonas fluorescens, in aquatic media.

274 In addition, hydroxylation of the aromatic ring of pyridinium-based ILs has also been reported 275 (Docherty et al. 2010), just as in case of triazole pesticides (WHO 2006). Therefore, similar 276 biotransformation mechanism cannot be ruled out for the three ILs containing triazolate-based 277 anion. Short-chained metabolites of ILs biotransformation typically have lower biodegradability 278 as compared to the parent compound (Jastorff et al. 2003; Neumann et al. 2014), which can 
279 explain primary biodegradation of up to ca. 30\% in our systems with no or small mineralization.

280 Although some potential biotransformation products, such as aldehydes or ethanol are toxic

281 toward microorganisms, (Stolte et al. 2008; Pham et al. 2009; Zhang et al. 2011),

282 biotransformation products with shorter side chains and ring hydroxylation products are typically

283 less toxic as compared to the parent compound (Docherty et al. 2010, Ranke et al. 2004; Stolte et

284 al. 2011). This may explain why no or very small inhibition of $\mathrm{CO}_{2}$ evolution from spiked

285 samples occurred during the course of the biodegradation experiment.

\section{4. Conclusions}

288 We showed that the four studied ammonium- and phosphonium-based ionic liquids were persistent in urban park soil microcosms. Primary biodegradation ranging from 21 to 33\% of total compound in the dissolved phase, combined with $\mathrm{CO}_{2}$ evolution from the microcosms being in range of soil background respiration rate, suggest no or very small mineralization of the primary compounds and/or their potential metabolites and no or negligible toxicity to soil

293 microorganisms.

\section{Acknowledgements}

296 This study was financed by funds granted by the National Science Centre in Poland conferred on 297 the basis of the decision nr DEC-2011/03/B/NZ9/00731.

\section{References}

300 Alef, K., Nannipleri, P., 1995. Methods in applied soil microbiology and biochemistry. Academic Press, San Diego, USA.

Alexander, M., 2000. Aging, bioavailability, and overestimation of risk from environmental pollutants. Environmental Science \& Technology 34, 4259-4265.

Atefi, F., Garcia, M.T., Singer, R.D., Scammells, P.J., 2009. Phosphonium ionic liquids: design, 
Cieniecka-Rosłonkiewicz, A., Pernak, J., Kubis-Feder, J., Ramani, A., Robertson, A.J., Seddon, K.R., 2005. Synthesis, anti-microbial activities and anti-electrostatic properties of phosphoniumbased ionic liquids. Green Chemistry 7, 855-862.

Coleman, D., Gathergood, N., 2010. Biodegradation studies of ionic liquids. Chemical Society Reviews 39, 600-637.

Cvjetko Bubalo, M., Radošević, K., Radojčić Redovniković, I., Halambek, J., Gaurina Srček V., 2014. A brief overview of the potential environmental hazards of ionic liquids. Ecotoxicology and Environmental Safety 99, 1-12.

Docherty, K.M, Joyce, M.V., Kulacki, K.J., Kulpa, C.F., 2010. Microbial biodegradation and metabolite toxicity of three pyridinium-based cation ionic liquids. Green Chemistry 12, 701-712.

Ford, L., Harjani, J.R., Atefi, F., Garcia, M.T., Singerc, R.D., Scammells, P.J., 2010. Further studies on the biodegradation of ionic liquids. Green Chemistry 12, 1783-1789.

Jastorff, B., Störmann, R., Ranke, J., Mölter, K., Stock, F., Oberheitmann, B., Hoffmann, W., Hoffmann, J., Nüchter, M., Ondruschkae, B., Filserb, J., 2003. How hazardous are ionic liquids? Structure-activity relationships and biological testing as important elements for sustainability evaluation. Green Chemistry 5, 136-142.

Lisiecki, P., Chrzanowski, Ł., Szulc, A., Ławniczak, Ł., Białas, W., Dziadas, M., Owsianiak, M., Staniewski, J., Cyplik, P., Marecik, R., Jeleń, H., Heipieper, H.J., 2014. Biodegradation of diesel/biodiesel blends in saturated sand microcosms. Fuel 116, 321-327.

Modelli, A., Sali, A., Galletti, P., Samorě C., 2008. Biodegradation of oxygenated and nonoxygenated imidazolium-based ionic liquids in soil. Chemosphere 73, 1322-1327.

Mrozik, W., Kotłowska, A., Kamysz, W., Stepnowski, P., 2012. Sorption of ionic liquids onto soils: Experimental and chemometric studies. Chemosphere 88, 1202-1207. 
341 Neumann, J., Cho, C.-W., Steudte, S., Köser, J., Uerdingen, M., Thöming, J., Stolte, S., 2012.

342 Biodegradability of fluoroorganic and cyano-based ionic liquid anions under aerobic and

343 anaerobic conditions. Green Chemistry 14, 410-418.

345 Neumann, J., Steudte, S., Cho, C.-W., Thöming, J., Stolte, S., 2014. Biodegradability of 27

346 pyrrolidinium, morpholinium, piperidinium, imidazolium and pyridinium ionic liquid cations

347 under aerobic conditions. Green Chemistry 16, 2174-2184.

OECD Guidelines for Testing of Chemicals 301: Ready Biodegradability, 1992. Organisation for 350 Economic Co-operation and Development, Paris, France.

Peric, B., Sierra, J., Martí, E., Cruañas, R., Garau, M.A., 2014. A comparative study of the terrestrial ecotoxicity of selected protic and aprotic ionic liquids. Chemosphere 108, 418-425. environmental acceptability. Chemical Society Reviews 40, 1383-1403.

Pham, T.P.T., Cho, C.-W., Jeon, C.-O., Chung, Y.-J., Lee, M.-W., Yun, Y.-S., 2009. methylpyridinium Bromide by Activated Sludge Microorganisms. Environmental Science \&

361 Technology 43, 516-521.

Pham, T.P.T., Cho, C.-W., Yun Y.-S., 2010. Environmental fate and toxicity of ionic liquids: A review. Water Research 44, 352-372.

Pisarova, L., Steudte, S., Dörr, N., Pittenauer, E., Allmaier, G., Stepnowski, P., Stolte, S., 2012.

367 Ionic liquid long-term stability assessment and its contribution to toxicity and biodegradation study of untreated and altered ionic liquids. Proceedings of the Institution of Mechanical Engineers, Part J: Journal of Engineering Tribology 226, 903-922. 
371 Plechkova, N.V, Seddon, K.R., 2008. Applications of ionic liquids in the chemical industry.

372 Chemical Society Reviews 37, 123-150.

373

374 Quijano, G., Couvert, A., Amrane, A., 2010. Ionic liquids: Applications and future trends in 375 bioreactor technology. Bioresource Technology 101, 8923-8930.

Quijano, G., Couvert, A., Amrane, A. , Darracq, G., Couriol, C., Cloirec, P.L., Paquin, L.,

378 Carrié, D., 2011. Toxicity and biodegradability of ionic liquids: New perspectives towards

379 whole-cell biotechnological applications. Chemical Engineering Journal 174, 27-32.

Ranke, J., Mölter, K., Stock, F., Bottin-Weber, U., Poczobutt, J., Hoffmann, J., Ondruschka, B., Filser, J., Jastorff, B., 2004. Biological effects of imidazolium ionic liquids with varying chain lengths in acute Vibrio fischeri and WST-1 cell viability assays. Ecotoxicology and Environmental Safety 58, 396-404. products - the example of ionic liquids. Chemical Reviews 107, 2183-2206.

Rogers, R.D., Seddon K.R., 2003. Ionic Liquids - Solvents of the Future? Science 302, 792-793.

Stepnowski, P., 2005. Preliminary assessment of the sorption of some alkyl imidazolium cations

Stolte, S., Abdulkarim, S., Arning, J., Blomeyer-Nienstedt A.-K., Bottin-Weber U., Matzke, M., Ranke, J., Jastorff B., Thöming J., 2008. Primary biodegradation of ionic liquid cations, identification of degradation products of 1-methyl-3-octylimidazolium chloride and 397 electrochemical wastewater treatment of poorly biodegradable compounds. Green Chemistry 10, 398 214-224.

399

400 Stolte, S., Steudte, S., Igartua, A., Stepnowski P., 2011. The Biodegradation of Ionic Liquids - the 401 View from a Chemical Structure Perspective. Current Organic Chemistry 15, 1946-1973. 
403 Studzińska, S., Sprynskyy, M., Buszewski, B., 2008. Study of sorption kinetics of some ionic

404 liquids on different soil types. Chemosphere 71, 2121-2128.

405

406 Szulc, A., Ambrożewicz, D., Sydow, M., Ławniczak, Ł., Piotrowska-Cyplik, A., Marecik, R., 407 Chrzanowski, Ł., 2014. The influence of bioaugmentation and biosurfactant addition on 408 bioremediation efficiency of diesel-oil contaminated soil: Feasibility during field studies. Journal 409 of Environmental Management 132, 121-128.

410

411 Walkiewicz, F., Materna, K., Kropacz, A., Michalczyk, A., Gwiazdowski, R., Praczyk, T.,

412 Pernak, J., 2010. Multifunctional long-alkyl-chain quaternary ammonium azolate-based ionic

413 liquids. New Journal of Chemistry 34, 2281-2289.

414

415 WHO 2006. Pesticide Residues in Food - 2004: Toxicological Evaluations: Joint Meeting of the 416 FAO Panel of Experts on Pesticide Residues in Food and the Environment and the WHO Core 417 Assessment Group, Rome, 20-29 September 2004.

418

419 Zhang, C, Malhotra, S.V., Francis, A.J., 2011. Toxicity of imidazolium- and pyridinium-based 420 ionic liquids and the co-metabolic degradation of N-ethylpyridinium tetrafluoroborate.

421 Chemosphere 82, 1690-1695. 


\section{Figure captions}

423 Fig. 1. Primary biodegradation (a), and sorption (b) of the studied ILs in soil microcosms after

424300 days. [DDA][3AT] is the didecyldimethylammonium 3-amino-1,2,4-triazolate, [BDA][3AT]

425 is the benzalkonium 3-amino-1,2,4-triazolate, [P66614][Cl] is the

426 trihexyl(tetradecyl)phosphonium chloride, [P66614][Tr] is the trihexyl(tetradecyl)phosphonium

427 1,2,4-triazolate. Bars represent standard errors of the mean $(n=9)$. Note, that primary

428 biodegradation of ammonium- and phosphonium-based ILs cannot be compared directly because

429 the phosphonium-based ILs anions could not be determined (see Methods section).

430

431 Fig. 2. Evolution of $\mathrm{CO}_{2}$ from soil microcosms over 300 days (a), and theoretical and observed

$432 \mathrm{CO}_{2}$ evolution at day 300 (b). The theoretical evolution is the expected $\mathrm{CO}_{2}$ evolution if all

433 primarily biodegraded IL had been mineralized. [DDA][3AT] is the didecyldimethylammonium

434 3-amino-1,2,4-triazolate, [BDA][3AT] is the benzalkonium 3-amino-1,2,4-triazolate,

$435[\mathrm{P} 66614][\mathrm{Cl}]$ is the trihexyl(tetradecyl)phosphonium chloride, [P66614][Tr] is the

436 trihexyl(tetradecyl)phosphonium 1,2,4-triazolate. Bars represent standard errors of the mean $(\mathrm{n}=$ 437 3). 


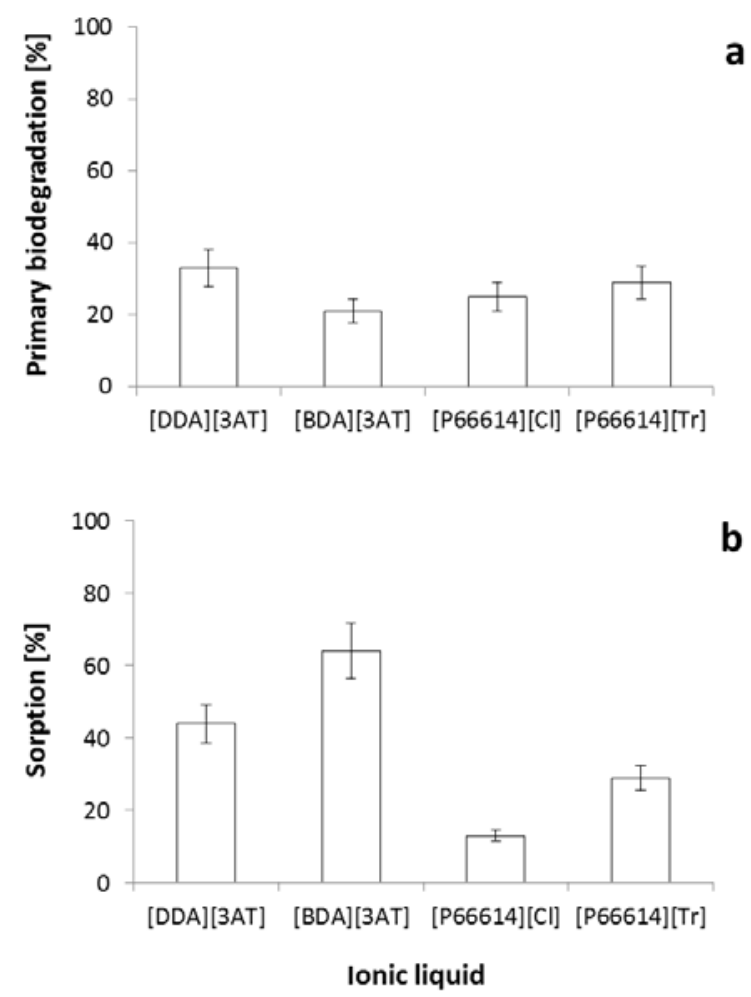

438

$439 \quad$ Fig. 1. 

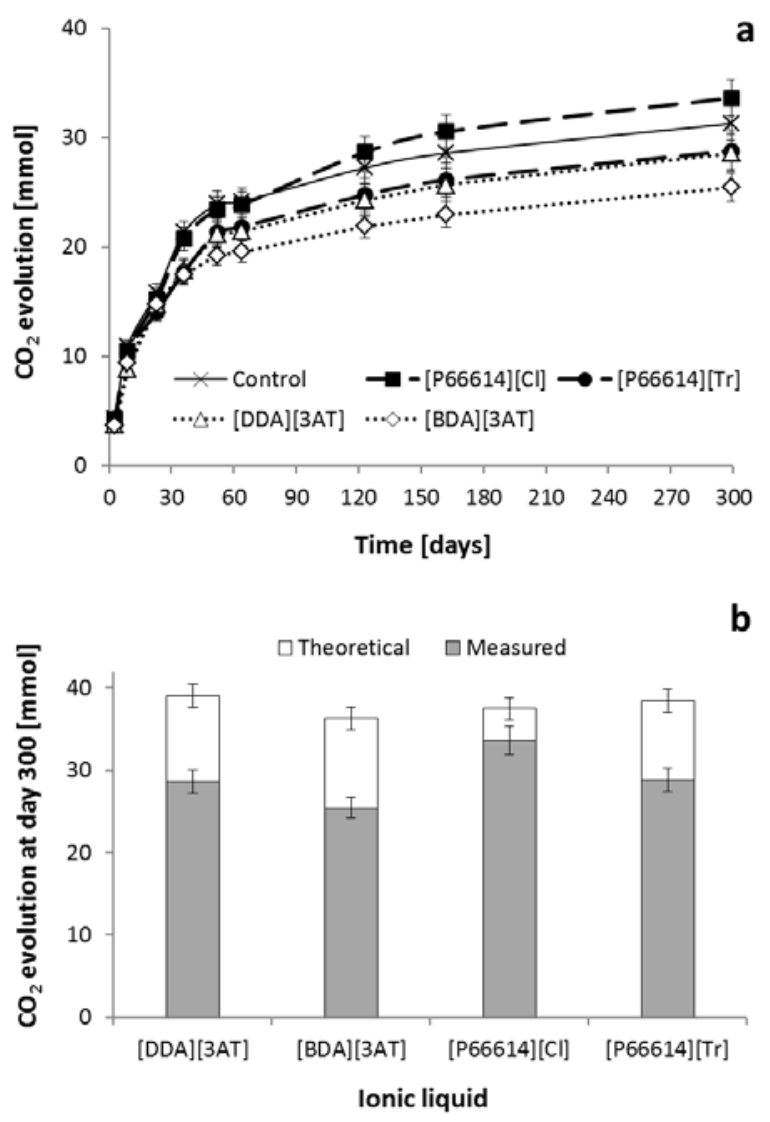

440

$441 \quad$ Fig. 2. 


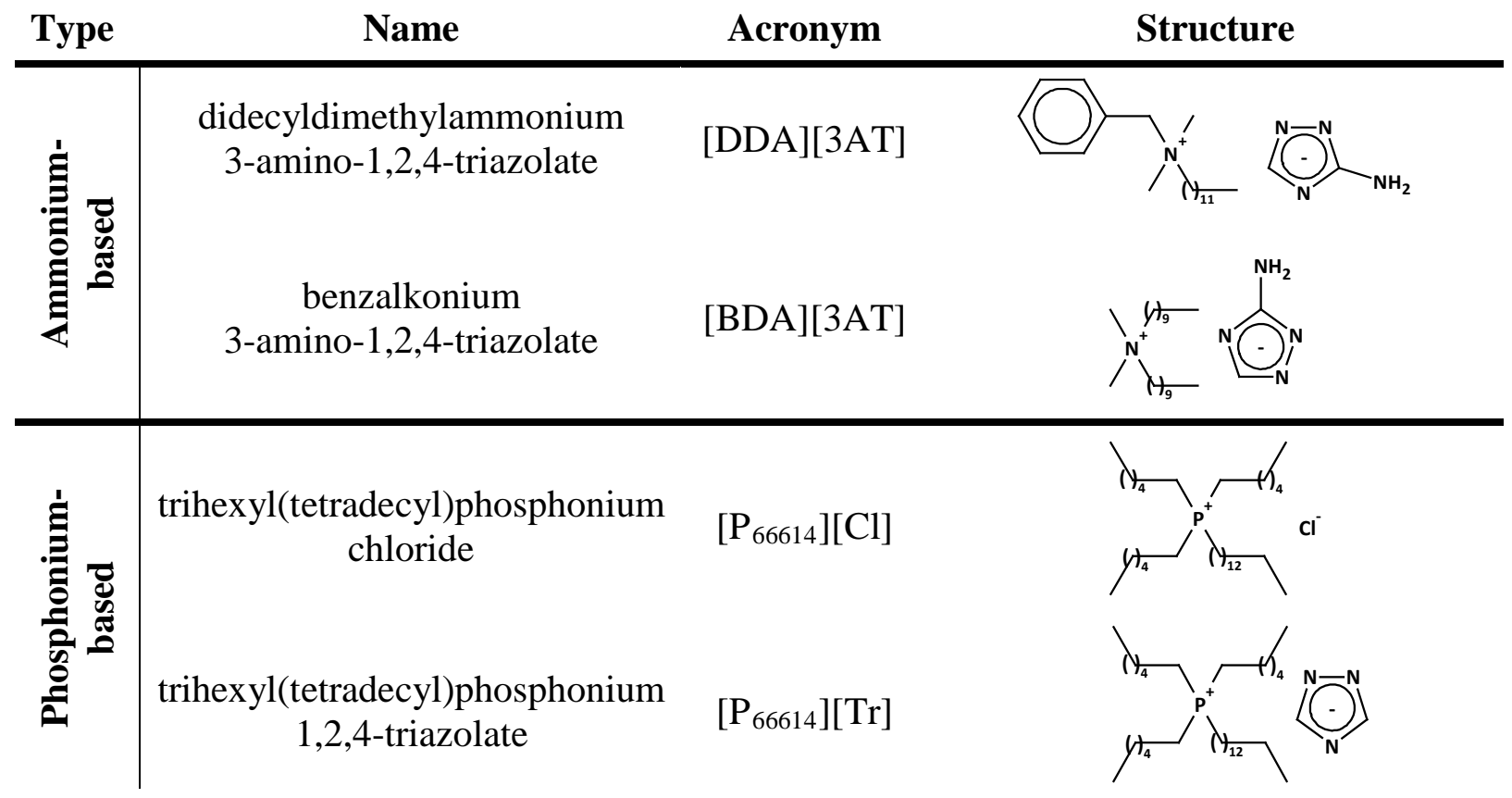

443

444 Table 1. Ionic liquids used during the study. 


\section{$445 \quad$ Highlights}

446 - The studied ILs show potential for long-term persistence in soils.

447 - Primary biodegradation of ILs ranged from 21 to 33\%.

$448-\mathrm{CO}_{2}$ evolution from the microcosms was in range of soil background respiration rate.

449 